\title{
Cognitive performance among breast cancer survivors treated with aromatase inhibitors
}

\author{
Ann B. Nattinger ${ }^{1,3}$, Liliana E. Pezzin ${ }^{1,3^{*}}$, June A. Restrepo ${ }^{2,3}$, Sally Durgerian², Mark G. Malkin² and Stephen M. Rao ${ }^{4}$ \\ *Correspondence: Ipezzin@mcw.edu \\ 'Department of Medicine and ${ }^{2}$ Neurology and ${ }^{3}$ Center for Patient Care and Outcomes Research, Medical College of Wisconsin, \\ 8701 Watertown Plank Road, Milwaukee, WI 53226, USA and ${ }^{4}$ Schey Center for Cognitive Neuroimaging, Cleveland Clinic, 9500 \\ Euclid Avenue, Cleveland, Ohio 44195.
}

\begin{abstract}
Background: The use of aromatase inhibitor (AI) therapy is increasing due to efficacy in decreasing breast cancer recurrence. There are theoretical reasons for concern about the effects of AI's on cognition, but few empiric studies have addressed this issue. We sought to assess cognitive function in relation to AI exposure.

Methods: Patients aged 65 or older at the time of an incident early-stage breast cancer underwent a battery of neuropsychological tests, as well as functional magnetic resonance imaging (fMRI) during an N-back cognitive task, which incrementally varies working memory load. Of 22 subjects, 11 had been treated with an AI for a mean of 37 months (AI group); 11 had no-AI exposure (no-AI group). The groups had similar distributions of age and educational achievement; no subject had received chemotherapy.

Results: The AI group did not differ significantly from the no-AI group on neuropsychological test scores. However there was a trend toward worse cognitive function among the AI subjects, who demonstrated worse performance on all 12 tests with a Cohen's d effect size of 0.3 or greater. During fMRI testing, the AI group failed to exhibit the expected pattern of increased regional blood oxygenation as the complexity of the working memory task increased. In contrast, the no-AI group showed the normally expected pattern of increased oxygenation as the demands on working memory increased. Conclusions: This study suggests the possibility of adverse effects of AI exposure on cognition, and suggests that fMRI may be sensitive to early changes in cognitive performance.
\end{abstract}

Keywords: Breast cancer, aromatase inhibitors, cognition, memory, fMRI

\section{Background}

Based on a reduction in breast cancer recurrence of about $50 \%$ in several randomized trials, the American Society of Clinical Oncology (ASCO) has recommended that therapy for postmenopausal women with hormone receptor-positive breast cancer include an aromatase inhibitor (Al) [1]. Since about $75 \%$ of the 180,000 women who develop breast cancer each year are aged 50 or older [2], and since the majority of postmenopausal women have hormone receptor-positive disease, this recommendation is likely to result in the exposure of a large number of women to Al agents.

Aromatase inhibitors markedly reduce circulating estrogen levels in postmenopausal women and little is known about their adverse effects. The ASCO technology assessment paper recommending $\mathrm{Al}$ agents specifically noted that information regarding the potential effects of Al's on cognition was lacking [1]. Estrogen receptors are found in many areas of the brain, and considerable evidence over the years has supported a positive relationship between estrogen and cognitive brain function, particularly with respect to verbal memory, attention, processing speed and working memory [3-6]. The evidence for this relationship was promising enough that the Women's Health Initiative Memory Study (WHIMS) randomized trial was conducted to evaluate the effect of estrogen on memory in a subset of the Women's Health Initiative trial [7]. Unexpectedly, this study not only failed to find a beneficial effect of estrogen, it found estrogen therapy associated with an increase in a combined endpoint of dementia and mild cognitive impairment [7].

The WHIMS findings have been interpreted by some as evidence that Als would be unlikely to cause cognitive problems. However, this is not necessarily the case. More detailed analyses of subsets of the WHIMS participants showed the possibility of different effects of estrogen with or without progesterone on different cognitive domains $[\mathbf{8 , 9}]$. There may be an optimal level of estrogen exposure, over which deleterious effects predominate [10]. The aromatase enzyme is widely distributed in neural tissue, $[6,11]$ and forms estrogen locally in neural tissue by converting precursor androgens [5]. Both estrogen and aromatase levels are markedly reduced in the autopsied brains of women with Alzheimer's Disease compared to control subjects without Alzheimer's Disease [5]. Given these 
Nattinger et al. Journal of Cancer Therapeutics and Research 2013,

considerations, it does not seem prudent to assume that the results of the WHIMS trial would necessarily imply the safety of the aromatase class of agents with respect to cognition [12]. Rather, that evidence should be determined empirically.

Assessing cognitive function through traditional neuropsychological testing is useful, but may be somewhat insensitive to adverse effects of a pharmacologic agent. Functional magnetic resonance imaging ( $\mathrm{fMRI}$ ) is a relatively new tool for noninvasive imaging of human brain function. Without the use of contrast agents, $\mathrm{FMRI}$ detects regional MR signal increases related to decreases in deoxyhemoglobin due to local increases in blood flow while accomplishing a task. Functional MRI imaging may prove to be more sensitive than traditional neuropsychological testing for detecting early changes predisposing to cognitive difficulties [13].

In this study, we compared cognitive function, as measured by traditional neuropsychological testing and by fMRI testing, in a cohort of breast cancer survivors who had been exposed to Al agents compared to a control cohort of breast cancer survivors without Al exposure. We hypothesized that fMRI might show evidence of the development of cognitive impairment even if not detected by traditional neuropsychological testing.

\section{Methods}

\section{Participants}

Participants were recruited from a larger cohort of women participating in a longitudinal National Cancer Institutesponsored survey study examining breast cancer outcomes among women aged 65 or older at the time of development of breast cancer in 2003 [14]. Subjects were considered for participation in this study if they were community-dwelling, resided within 100 miles of our academic health center, had provided valid responses to survey questions regarding use of hormonal therapies for their breast cancer, and had not received any chemotherapy as part of their breast cancer treatment. The study was approved by the Medical College of Wisconsin IRB and written informed consent was obtained. All participants received financial compensation.

\section{Neuropsychological Testing}

A battery of standardized neuropsychological tests was administered to participants in a fixed order over approximately 90 minutes. The specific tests administered are listed in Table 1. Unpaired T-tests were conducted on each neuropsychological domain. We applied a more conservative 0.01 alpha level to account for multiple comparisons.

\section{fMRI Task}

The $N$-back task is a parametrically designed sequential letter task, which incrementally varies working memory load at four levels: 0-back, 1-back, 2-back and 3-back [15]. In each run, participants were presented with a pseudorandom series of 120 upper- or lower-case letters every 3 seconds in 45-second blocks. The stimuli were presented for a duration of $500 \mathrm{~ms}$ with an interstimulus interval of $2500 \mathrm{~ms}$. Each run began with a 24-second rest period, followed by four blocks of N-back in pseudorandom order, a rest period, four more blocks of N-back, and rest. While the blocks of stimuli were similar, task difficulty varied for each block. In 0-back blocks, participants were instructed to press the index finger when the letter " $d$ " appeared. In 1-back blocks, participants were instructed to make a key press whenever a letter appeared that was the same as the letter preceding it. Similarly, in 2-back blocks, the target was a letter that was the same as the antepenultimate letter, and in 3-back blocks, the preantepenultimate letter. The 0-back condition, which does not involve working memory but does require attention to a task, served as a control condition. Subjects were provided practice runs prior to scanning to ensure that they correctly understood the task.

To evaluate performance on the $\mathrm{N}$-back task, measurements were made of the accuracy and reaction time associated with each condition, across all imaging runs. Analyses of variance (ANOVA) were performed, examining main effects and interactions of working memory load (0-back, 1-back, 2-back and 3-back) and treatment group.

\section{fMRI Acquisition}

Whole-brain functional MRI was conducted on a General Electric (Waukesha, WI) 3.0 Tesla short bore scanner equipped with a single channel head coil. fMRI images were collected using an gradient-echo, echoplanar pulse sequence ( $T E=$ 25 msec; flip angle $=77$ degrees; field of view (FOV) $=24$ $\mathrm{cm}$; matrix 64x64). Thirty-six contiguous axial, 4-mm-thick slices were selected to provide coverage of the entire brain (voxel size $=3.75 \times 3.75 \times 4 \mathrm{~mm}$ ). The interscan interval (TR) was 2 seconds. High-resolution, three-dimensional spoiled gradient-recalled at steady-state (SPGR) anatomic images were also acquired ( $T E=3.2 \mathrm{msec}$; $\mathrm{TR}=9.5 \mathrm{msec}$; inversion recovery (IR) preparation time $=450 \mathrm{msec}$; flip angle $=12$ degrees; number of excitations $(\mathrm{NEX})=1$; slice thickness = $1.0 \mathrm{~mm} ; \mathrm{FOV}=24 \mathrm{~cm}$; resolution $=256 \times 224$ ).

Visual stimuli were computer-generated and rear-projected (Sharp model XG2000U video projector) on an opaque screen located at the subject's head. Subjects viewed the screen through prism glasses attached to the head coil. A non-ferrous keypress device made from four force-sensing resistors was used to record accuracy and reaction time through the parallel port of an IBM compatible computer.

\section{fMRI Analysis}

To evaluate hypotheses regarding neural activation patterns, the raw $\mathrm{fMRI}$ signal data were analyzed using Analysis of Functional Neurolmages (AFNI) [16]. Each image time series was time-shifted to the beginning of the TR and then spatially registered to reduce the effects of head motion using a rigid body iterative linear least squares method. Multiple regression 
Nattinger et al. Journal of Cancer Therapeutics and Research 2013, http://www.hoajonline.com/journals/pdf/2049-7962-2-7.pdf

doi: $10.7243 / 2049-7962-2-7$

Table 1. Differences in Raw Neuropsychological Test Scores Between Groups Exposed and Not Exposed to Aromotase Inhibitors.

\begin{tabular}{|c|c|c|c|c|c|}
\hline $\begin{array}{l}\text { Neuropsychological } \\
\text { Domain }\end{array}$ & Test & $\begin{array}{c}\text { AI } \\
\text { mean }(\mathrm{SD}) \\
(\mathbf{n}=11)\end{array}$ & $\begin{array}{c}\text { No AI } \\
\text { mean }(\mathrm{SD}) \\
(\mathrm{n}=11)\end{array}$ & $p$ & $d$ \\
\hline \multirow{6}{*}{$\begin{array}{l}\text { Attention/ } \\
\text { Working Memory }\end{array}$} & Trail Making Test, & & & & \\
\hline & Condition 2 (sec) [26] & $44.8(17.1)$ & $40.1(10.0)$ & 0.44 & 0.3 \\
\hline & Trail Making Test, Condition 4 (sec) [26] & $101.3(23.5)$ & $95.5(34.4)$ & 0.65 & 0.2 \\
\hline & Trail Making Test, 4-2 (sec) [26] & 56.5 & 55.4 & - & - \\
\hline & $\begin{array}{l}\text { Digit Span Forward and Back } \\
\text { (avg number correct) [27] }\end{array}$ & $8.1(1.7)$ & $8.5(2.3)$ & 0.64 & 0.2 \\
\hline & SDMT (num correct) [28] & $43.1(11.0)$ & $41.73(8.4)$ & 0.72 & 0.1 \\
\hline \multirow[t]{3}{*}{ Executive Function } & Similarities (num correct) [29] & $31.2(9.5)$ & $36.1(4.0)$ & 0.13 & 0.7 \\
\hline & COWAT (F-A-S) (num correct) [30] & $37.3(9.6)$ & $37.6(7.9)$ & 0.94 & 0.0 \\
\hline & Category Fluency (num correct) [30] & $18.4(4.1)$ & $18.1(4.7)$ & 0.87 & 0.1 \\
\hline \multirow[t]{3}{*}{ Episodic Memory } & Logical Memory I \& II (avg num correct) [31] & $25.6(5.9)$ & $27.7(9.3)$ & 0.63 & 0.3 \\
\hline & BVMT Total Recall (num correct) [32] & $14.3(5.8)$ & $19.0(5.8)$ & 0.07 & 0.8 \\
\hline & RAVLT Total Recall (num correct) [33] & $45.7(7.3)$ & $49.6(8.8)$ & 0.27 & 0.5 \\
\hline Language & Boston Naming Test (num correct)[34] & $53.0(8.1)$ & $55.5(3.4)$ & 0.36 & 0.4 \\
\hline Visuospatial Function & Block Design (num correct)[29] & $26.7(14.5)$ & $31.5(11.2)$ & 0.39 & 0.4 \\
\hline \multicolumn{2}{|c|}{ Global Cognitive Function DRS-2 (num correct)[35] } & $137.4(4.6)$ & $138.8(3.1)$ & 0.41 & 0.4 \\
\hline & MMSE (num correct)[36] & $26.7(2.2)$ & $27.5(2.5)$ & 0.43 & 0.3 \\
\hline \multirow[t]{2}{*}{ Motor } & Grooved Pegboard, Dom (secs)[37] & $101.2(21.2)$ & $95.8(19.4)$ & 0.54 & 0.3 \\
\hline & Grooved Pegboard, non-Dom (secs)[37] & $117.0(30.0)$ & $104.5(19.5)$ & 0.26 & 0.5 \\
\hline \multirow[t]{3}{*}{ Self-Report Measures } & GDS (total num) [38] & $4.8(4.3)$ & $4.6(5.6)$ & 0.93 & 0.0 \\
\hline & $\begin{array}{l}\text { FrSBe Self Total } \\
\text { (avg Before and After total)[39] }\end{array}$ & $83.4(19.6)$ & 77.9 (14.7) & 0.46 & 0.2 \\
\hline & $\begin{array}{l}\text { FrSBe Family Total } \\
\text { (avg Before and After total)[39] }\end{array}$ & $83.1(28.7)$ & $67.8(16.2)$ & 0.14 & 0.7 \\
\hline
\end{tabular}

Note: AI=Aromatase Inhibitor, $\mathrm{Sec}=$ seconds, Num=number, COWAT=Controlled Oral Word Association Test, BVMT-R=Brief

Visuospatial Memory Test, Revised, RAVLT=Rey Auditory Verbal Learning Test, SDMT=Symbol Digit Modalities Test, DRS-2=Dementia Rating Scale-2, MMSE-Mini Mental State Exam, GDS-Geriatric, Depression Scale, FrSBE-Frontal Systems Behavior Scale, Dom=Dominant hand, $d$ represents effect size. Performance comparison: AI- No AI $\neq 0$. An overall MANOVA showed no significant group differences $(\mathrm{p}=0.42)$.

was used to extract a hemodynamic response magnitude for each of the four stimulus conditions $(0-, 1-, 2-$ or 3-back). To compensate for normal variation in anatomy across subjects, functional images were blurred using a $6 \mathrm{~mm}$ Gaussian fullwidth half-maximum filter, reformatted into $1 \mathrm{~mm}$ isotropic voxels and transformed into standard stereotaxic space $[17,18]$.

Statistical analysis consisted of a voxel-wise, 2 X 4 (Group by Back) repeated measures analysis of variance (ANOVA). An individual voxel probability threshold of 0.003 was applied in conjunction with a minimum cluster size threshold of 0.506 $\mathrm{ml}$ [19] to minimize false positive activation foci from the brain maps. These two threshold values were derived from a Monte Carlo simulation (3,000 iterations) using the AFNI AlphaSim program to achieve a family-wise error of $p<0.05$.

\section{Results}

\section{Sample Characteristics}

Of 107 women contacted, 55 declined participation citing long distance (44), lack of transportation or caregiver to accompany them (8) and excessive time commitment (3) as the main reason for declining. Of the 52 who agreed to consider participation, 26 were excluded due to: claustrophobia (12), metal in body (5), physically unable to lie down in the scanner (4), height/weight incompatible with the scanner (2), cancer other than breast (1), low visual acuity (2). Of the 26 who participated, 4 were excluded from analyses due to: inability to complete fMRI (1), technical problems with the fMRI analysis (2), and receipt of Al therapy for a single month (1).

Of the 22 included in analyses, 11 had received adjuvant hormonal therapy including at least 12 months Al therapy ("Al group"). The remaining 11 had received no Al therapy ("No-Al group"). Three Al subjects had a history of tamoxifen treatment for a median of 21 months. Three No-Al subjects had tamoxifen exposure: two were currently using it and one had used it until 9 months prior to testing. The median tamoxifen exposure for these three subjects was 42 months. 
Nattinger et al. Journal of Cancer Therapeutics and Research 2013,

http://www.hoajonline.com/journals/pdf/2049-7962-2-7.pdf

doi: $10.7243 / 2049-7962-2-7$

Table 2. Spatial extend of activation due to increased N-Back task difficulty.

\begin{tabular}{|c|c|c|c|c|c|c|c|c|c|c|}
\hline \multirow{3}{*}{$\begin{array}{l}\text { Lobe } \\
\text { Frontal }\end{array}$} & \multirow{3}{*}{ Region } & \multirow[b]{2}{*}{ BA } & \multicolumn{3}{|c|}{ AI } & \multirow{3}{*}{ vol. $(m l)$} & \multicolumn{3}{|c|}{ no AI } & \multirow[b]{2}{*}{ vol. $(m l)$} \\
\hline & & & $x$ & $\mathbf{y}$ & $\mathbf{z}$ & & $\mathbf{x}$ & y & z & \\
\hline & & & & & & & & & & \\
\hline $\mathrm{L}$ & Middle Frontal, Precentral Gyrus & & & & & & -38 & 14 & 28 & 9.2 \\
\hline $\mathrm{L}$ & Precentral Gyrus & 4,6 & & & & & -37 & -1 & 40 & 9.0 \\
\hline L & Middle Frontal Gyrus & 6 & & & & & -22 & -2 & 54 & 8.2 \\
\hline $\mathrm{R}$ & Precentral Gyrus & 6,44 & & & & & 44 & 4 & 35 & 5.9 \\
\hline $\mathrm{R}$ & Middle Frontal Gyrus & 6 & & & & & 28 & -1 & 52 & 5.1 \\
\hline $\mathrm{R}$ & Middle Frontal Gyrus & 9 & & & & & 41 & 23 & 33 & 3.6 \\
\hline $\mathrm{L}$ & Middle Frontal Gyrus & 10,46 & & & & & -32 & 38 & 19 & 1.4 \\
\hline $\mathrm{R}$ & Middle Frontal Gyrus & 10,46 & & & & & 31 & 41 & 19 & 0.5 \\
\hline B & Anterior Cingulate & $9,24,32$ & & & & & 1 & 45 & 16 & 5.4 \\
\hline B & SMA & 6,32 & & & & & -1 & 3 & 53 & 4.9 \\
\hline B & Pre SMA & 8,32 & & & & & 5 & 18 & 44 & 4.2 \\
\hline \multicolumn{11}{|c|}{ Parietal } \\
\hline L & Inferior Parietal Lobule & 7 & & & & & .33 & -53 & 41 & 241 \\
\hline $\mathrm{R}$ & Inferior Parictal Lobule & 7 & & & & & 36 & -55 & 39 & 11.8 \\
\hline B & Precuneus & & & & & & 3 & -69 & 48 & 7.2 \\
\hline $\mathrm{R}$ & Inferior Parietal Lobule & 7,40 & & & & & 47 & -50 & 46 & 2.4 \\
\hline L & Posterior Cingulate & 31 & -9 & -57 & 20 & 0.74 & -7 & -56 & 23 & 2.1 \\
\hline $\mathrm{R}$ & Cuncus & $18, \mathrm{~V} 3$ & & & & & 14 & -86 & 22 & 0.5 \\
\hline \multicolumn{11}{|c|}{ Temporal } \\
\hline L & Insula Lobe & 13 & & & & & .29 & 17 & 10 & 1.0 \\
\hline $\mathrm{L}$ & Inferior Temporal Gyrus & 37 & & & & & -45 & -44 & -10 & 0.6 \\
\hline \multicolumn{11}{|c|}{ Occipital } \\
\hline $\mathrm{L}$ & Middle Occipital Gyrus & 18 & & & & & -17 & -85 & -5 & 0.7 \\
\hline $\mathrm{R}$ & Middle Occipital Gyrus & 17,18 & & & & & 22 & -86 & -2 & 0.5 \\
\hline \multicolumn{11}{|c|}{ Subcortical } \\
\hline $\mathrm{L}$ & Thalamus & & & & & & -13 & -17 & 16 & 2.0 \\
\hline $\mathrm{L}$ & Cerebellum(VI) & & & & & & -24 & -56 & -26 & 8.5 \\
\hline $\mathrm{R}$ & Cerebellumand Vermis (V) & & & & & & 26 & -62 & -23 & 6.5 \\
\hline L & Cerebellum(VI, Crus 1) & & & & & & -8 & -64 & -24 & 1.7 \\
\hline $\mathrm{R}$ & Corebellum(VIII, VII) & & & & & & 34 & -57 & -43 & 0.6 \\
\hline
\end{tabular}

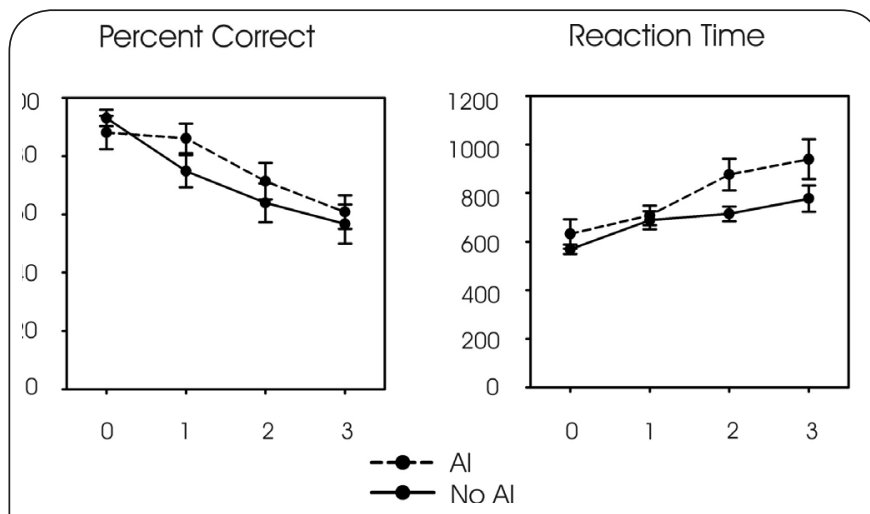

Figure 1. Performance on the N-Back task for the two treatment groups. Reaction time $=$ milliseconds. $\mathrm{X}$-axis $=$ N-Back difficulty level.

Ages for the entire sample ranged from 69 to 80 years, and education levels from 12 to 18 years. Within the Al group, the mean age was 74.6 years $(S D=2.4)$, mean education level was 14.6 years $(S D=2.5)$, and the mean duration of Al treatment was 37 months $(S D=12.1)$. All women were still on the $A l$ at the time of testing, except for one who stopped Al therapy one month prior to testing. Within the No-Al group, the mean age was 75.6 years $(S D=2.5)$, and mean education level was 14.8 years $(S D=2.5)$. The two groups did not differ in terms of age $(t=-.77, p=.45)$ or education $(t=-.17, p=.86)$. There were no significant differences between groups in the initial stage of disease ( $41 \%$ localized, $54 \%$ regional, $5 \%$ unknown), receipt of mastectomy $(41 \%)$, time from surgery to testing (mean of 41 months, $S D=3$ ) or of handedness (91\% right-handed).

\section{Neuropsychological and fMRI Test Performance}

Results of the neuropsychological test battery are detailed in Table 1. No statistically significant differences were found between the groups; however, a pattern of poorer performance emerged in the Al group. Because of the small sample size, we examined the effect size, Cohen's $d$, as an indicator of performance. For any effect size of .3 or greater, the direction of the performance was indicated in the "Performance Comparison" column of Table 1. For all 12 neuropsychological test measures with an effect size of 0.3 or greater, the Al group performed more poorly than the No-Al group, suggesting that group differences might have emerged with larger sample sizes.

Performance on the N-Back task is illustrated in Figure 1. The effects of working memory load and treatment group and their interactions were analyzed using separate analyses of variance (ANOVAs) performed on the accuracy (percent correct) and reaction time (msec) dependent measures. As expected, the main effect of working memory load for accuracy $\left(F_{3,42}=28.2, p<0.0001\right)$ and reaction time were highly significant $\left(F_{3,42}=19.6, p<0.0001\right)$. For both the accuracy and 
Table 3. Voxelwise Analysis of Group x Memory Load Interaction Effects

\begin{tabular}{|c|c|c|c|c|c|c|}
\hline \multicolumn{2}{|c|}{ Region } & \multirow[t]{2}{*}{ BA } & \multirow[t]{2}{*}{$\mathbf{x}$} & \multirow[t]{2}{*}{$\mathbf{y}$} & \multirow[t]{2}{*}{$\mathbf{z}$} & \multirow[t]{2}{*}{ Volume $(\mathrm{mL})$} \\
\hline & obe & & & & & \\
\hline $\mathrm{L}$ & Middle Frontal Gyrus, Precentral Gyrus & 6 & -33 & 0 & 43 & 1.7 \\
\hline $\mathrm{R}$ & Middle Frontal Gyrus, Precentral Gyrus & 6 & 45 & 1 & 39 & 1.4 \\
\hline $\mathrm{L}$ & Inferior Frontal Gyrus, Middle Frontal Gyrus & 46 & -37 & 35 & 15 & 0.6 \\
\hline
\end{tabular}

Note: $\mathrm{BA}=$ Brodmann's area, $\mathrm{L}=\mathrm{Left}, \mathrm{R}=$ Right, $x y z$ coordinates are based on Talairach and Tourneau (1988)

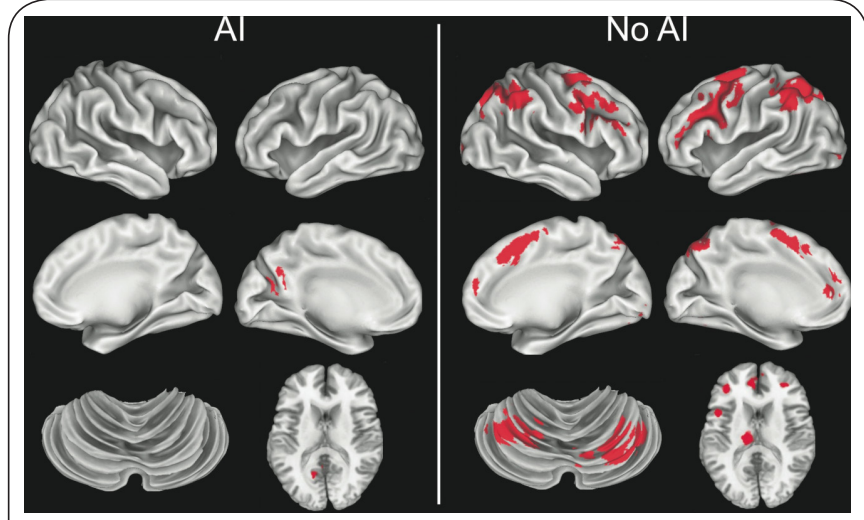

Figure 2. Brain regions demonstrating increasing activation as a function of working memory load. Voxel-wise analysis performed separately for each group. Axial section is located at $\mathrm{z}=15 \mathrm{~mm}$. See Table $\mathbf{2}$ for region volumes and stereotaxic coordinates.

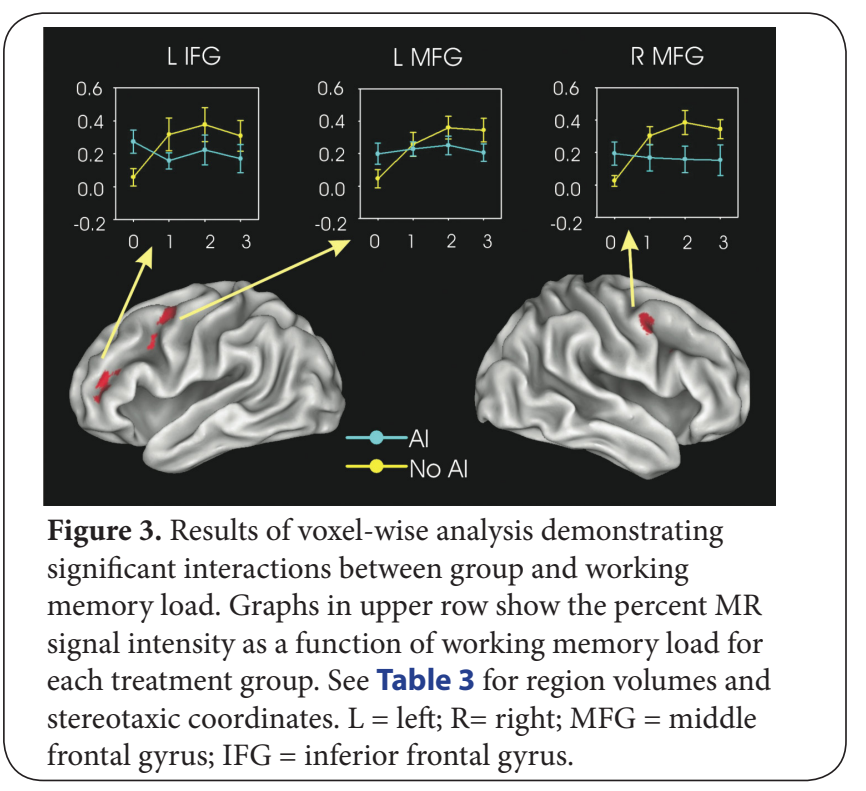

reaction time measures, neither the treatment group nor the group by working memory load interaction effects were significant $(p>0.05)$.

\section{fMRI Results}

Regions showing significant activation differences as a function of working memory load were identified for the $\mathrm{Al}$ and no-Al groups separately using voxelwise one-way ANOVAs across the $\mathrm{N}$-back conditions (Figure 2 and Table 2). In the no-Al group, 26 regions demonstrated a pattern of activation that increased with working memory load (depicted in red on Figure 2). In the Al group, only one relatively small region in the left posterior cingulate showed a significant correlation with working memory difficulty (Figure 2, Table 2). In a subgroup analysis omitting the three subjects in each group with current or prior exposure to tamoxifen, the results were essentially unchanged.

On a voxel-wise 2 (Group) X 4 (n-back) repeated measures ANOVA, significant interaction effects were observed in three regions typically associated with working memory: left and right middle frontal and left inferior frontal regions (Figure 3, Table 3). Whereas the no-Al group showed the expected pattern of increasing levels of activation as working memory load increased, the Al group showed a flat pattern in which brain activation did not increase with task difficulty.

\section{Discussion}

In this study, breast cancer survivors with a mean of just over three years of exposure to an Al did not differ statistically from breast cancer survivors with no Al exposure with respect to traditional neuropsychological testing. However, a trend toward worse cognitive function among the women exposed to an Al was found on most of these measures, as demonstrated by moderate to large effect sizes (Cohen's $d>0.3$ ). In contrast, on $\mathrm{FMRI}$, the number of brain regions demonstrating the expected increase in $\mathrm{fMRl}$ activation with working memory load was considerably greater in the no-Al group $(n=26)$ than the $\mathrm{Al}$ group $(\mathrm{N}=1)$. In a separate voxel-wise analysis, three working memory regions in the frontal cortex demonstrated the expected increase in $\mathrm{fMRI}$ activation [20] with memory load in the breast cancer survivors with no prior Al exposure. The Al group, however, failed to demonstrate an increase in activation as the demands on working memory increased in these three regions.

This pattern of aberrant activation has been observed in other conditions involving mild brain dysfunction. Using the $\mathrm{N}$-back task in recently injured subjects with mild traumatic brain injury (TBI), McAllister and colleagues observed a smaller increase in bilateral frontal and parietal activation during the high-processing load conditions when compared with controls [21]. They hypothesized that limitations in the allocation of 
Nattinger et al. Journal of Cancer Therapeutics and Research 2013,

processing resources occur at the highest levels of N-back difficulty in their TBI patients. We speculate that a similar effect may be present in Al-exposed patients.

Only a small number of papers have reported directly on cognitive function among women treated with Als, and these have conflicting results. Jenkins and colleagues [22] evaluated traditional neuropsychological measures in a sample of women participating in a randomized trial of anastrozole (an Al agent), tamoxifen, or both, and compared them to a controls without breast cancer. The breast cancer patients were impaired with regard to processing speed and immediate verbal memory. It is not clear what percentage of the subjects had exposure only to tamoxifen, and not to the Al agent. Bender and colleagues [23] studied 31 postmenopausal women aged 21 to 65 , and compared anastrozole recipients to tamoxifen recipients. Some of the women in each group had received cytotoxic chemotherapy. The women taking anastrozole had worse cognitive function than the women taking tamoxifen. The IBIS II study evaluated cognition prospectively in 207 women at high risk for breast cancer, who were randomized to prophylactic therapy with anastrozole or placebo [24]. At 24 months, cognitive performance did not differ. These women were much younger (mean age 57 years) than our cohort, as well as having a shorter exposure time to the Al. The older age of our cohort is worth noting, as older women may be more vulnerable to loss of cognitive function via a number of pathways [10].

The current report advances the literature by evaluating cognitive function not only with traditional neuropsychological measures, but also with task-activated fMRI. We were able to show dramatic group differences in the pattern of brain activation with only 11 patients in each group. These fMRI group differences were observed in the absence of significant effects on neuropsychological testing and suggest that this functional imaging tool may be more sensitive in detecting the neurocognitive brain changes than standardized neuropsychological tests in the context of a randomized clinical trial. To illustrate this point, for a given neuropsychological test with an estimated effect size of 0.7 , a clinical trial with $80 \%$ power would require 50 subjects per group; for a test with an effect size of 0.3 , a sample size of 262 subjects would be required per group. In contrast, we observed clear group differences using fMRI on only 11 patients per group. This study has limitations. The sample size was small, so the power to detect statistically significant effects between the treated and untreated groups in the neuropsychological battery of tests was modest. This may account for the lack of significant group differences observed on traditional neuropsychological measures. However, the modest sample size makes the differences observed with $\mathrm{fMRI}$ that much more remarkable. The patients were not randomly allocated to treatment with the Al agent, so it is possible that there was selection bias with respect to the treatment groups. Specifically, one might expect that the women treated with the newer Al agents would have higher educational attainment and cognitive performance $[40,41]$. However, the age and educational distribution of the treated and untreated subjects was very similar.

A further consideration is that the study was cross-sectional in design, and cognitive measures were not available prior to treatment. While a longitudinal design would be preferable, the control group did consist of breast cancer survivors. This is an important advance over some prior studies as breast cancer survivors may have different cognitive performance than women without breast cancer [25]. Finally, three of the subjects in both the Al and no-Al groups had undergone prior treatment with tamoxifen. Tamoxifen may cause cognitive decline, although the current literature is conflicting $[4,6]$. However, the No-Al subjects had double the tamoxifen exposure of the Al subjects. Therefore, if tamoxifen does cause cognitive decline, the No-Al group should have exhibited worse cognition than the Al group. For this reason, tamoxifen exposure would not explain the abnormal fMRI findings among the Al group.

\section{Conclusions}

In summary, women treated with Al agents exhibited an abnormal pattern of fMRI brain activation and a tendency toward worse cognitive performance on traditional neuropsychological measures than women not treated with Al agents. The use of these agents is likely to increase dramatically due to their efficacy in preventing breast cancer recurrence among postmenopausal women with hormone receptor-positive cancer. Results from this pilot study indicate the possibility of deleterious effects on brain function of Al agents that require replication in a larger trial. If the results are confirmed, one could imagine a future role of $\mathrm{fMRI}$ in screening patients who are on Al medications for early decrements in cognitive function so that the individual risk-benefit ratio can be reassessed. Patients with early cognitive decrements might also be good candidates for participation in trials of agents designed to ameliorate such effects.

\section{Competing interests}

The authors declare that they have no competing interests.

\section{Authors' contributions}

$A B N$ and LEP were responsible for study design, statistical analyses, and manuscript writing. JAR was responsible for patient enrollment and for collecting data on the battery of neuropsychological tests. SD conducted and analyzed data from the fMRI studies. MGM and SMR provided expertise with interpretation of fMRI findings. All authors read and approved the final manuscript.

\section{Acknowledgement}

This research was supported by Grant Number R01-CA81379 from the National Cancer Institute and Grant Number 5520040 from the Medical College of Wisconsin Advancing a Healthier Wisconsin program (to Dr. Ann Nattinger).

Publication history

Received: 39-Nov-2012 Revised: 17-Jan-2013

Accepted: 25-Jan-2013 Published: 01-Feb-2013 


\section{References}

1. Winer EP, Hudis C, Burstein HJ, Wolff AC, Pritchard KI, Ingle JN, Chlebowski RT, Gelber R, Edge SB, Gralow J, Cobleigh MA, Mamounas EP, Goldstein LJ, Whelan TJ, Powles TJ, Bryant J, Perkins C, Perotti J, Braun S, Langer AS, Browman GP and Somerfield MR: American Society of Clinical Oncology technology assessment on the use of aromatase inhibitors as adjuvant therapy for postmenopausal women with hormone receptorpositive breast cancer: status report 2004. J Clin Oncol 2005, 23:619-29. | Article | PubMed

2. SEER Cancer Statistics Review, 1975-2005. National Cancer Institute. | Website

3. Duff SJ and Hampson E: A beneficial effect of estrogen on working memory in postmenopausal women taking hormone replacement therapy. Horm Behav 2000, 38:262-76. | Article | PubMed

4. Shilling $V$, Jenkins $V$, Fallowfield $L$ and Howell $A$ : The effects of oestrogens and anti-oestrogens on cognition. Breast 2001, 10:484-91. | Article | PubMed

5. Yue X, Lu M, Lancaster T, Cao P, Honda S, Staufenbiel M, Harada N, Zhong $Z$, Shen $Y$ and Li R: Brain estrogen deficiency accelerates Abeta plaque formation in an Alzheimer's disease animal model. Proc Natl Acad Sci U S A 2005, 102:19198-203. | Article | PubMed Abstract | PubMed Full Text

6. Jenkins $V$, Atkins $L$ and Fallowfield $L$ : Does endocrine therapy for the treatment and prevention of breast cancer affect memory and cognition? Eur J Cancer 2007, 43:1342-7. | Article I PubMed

7. Shumaker SA, Legault C, Kuller L, Rapp SR, Thal L, Lane DS, Fillit H, Stefanick ML, Hendrix SL, Lewis CE, Masaki K and Coker LH: Conjugated equine estrogens and incidence of probable dementia and mild cognitive impairment in postmenopausal women: Women's Health Initiative Memory Study. JAMA 2004, 291:2947-58. | Article | PubMed

8. Resnick SM, Maki PM, Rapp SR, Espeland MA, Brunner R, Coker LH, Granek IA, Hogan P, Ockene JK and Shumaker SA: Effects of combination estrogen plus progestin hormone treatment on cognition and affect. J Clin Endocrinol Metab 2006, 91:1802-10. | Article | PubMed

9. Resnick SM, Espeland MA, An Y, Maki PM, Coker LH, Jackson R, Stefanick $M L$, Wallace $R$ and Rapp SR: Effects of conjugated equine estrogens on cognition and affect in postmenopausal women with prior hysterectomy. J Clin Endocrinol Metab 2009, 94:4152-61. | Article | PubMed Abstract | PubMed Full Text

10. Resnick SM, Espeland MA, Jaramillo SA, Hirsch C, Stefanick ML, Murray AM, Ockene J and Davatzikos C: Postmenopausal hormone therapy and regional brain volumes: the WHIMS-MRI Study. Neurology 2009, 72:13542. | Article | PubMed Abstact | PubMed Full Text

11. Garcia-Segura LM: Aromatase in the brain: not just for reproduction anymore. J Neuroendocrinol 2008, 20:705-12. | Article I PubMed

12. Birge SJ: Aromatase inhibitors: a time for reflection. Menopause 2007, 14:971-2. | Article | PubMed

13. Zimbelman JL, Paulsen JS, Mikos A, Reynolds NC, Hoffmann RG and Rao SM: fMRI detection of early neural dysfunction in preclinical Huntington's disease. J Int Neuropsychol Soc 2007, 13:758-69. | Article | PubMed

14. Nattinger AB, Pezzin LE, Sparapani RA, Neuner JM, King TK and Laud PW: Heightened attention to medical privacy: challenges for unbiased sample recruitment and a possible solution. Am J Epidemiol 2010, 172:637-44. | Article | PubMed Abstract | PubMed Full Text

15. Nystrom LE, Braver TS, Sabb FW, Delgado MR, Noll DC and Cohen JD: Working memory for letters, shapes, and locations: fMRI evidence against stimulus-based regional organization in human prefrontal cortex. Neuroimage 2000, 11:424-46. | Article | PubMed

16. Cox RW and Hyde JS: Software tools for analysis and visualization of fMRI data. NMR Biomed 1997, 10:171-8. | Article | PubMed

17. Talairach J, Tourneau P: Co-Planar Stereotaxic Atlas of the Human Brain. Stuttgart, Germany: Georg Thieme Verlag, 1988.

18. Schmahmann J, Doyon J, Toga A, Petrides M, Evans A: MRI Atlas of the Human Cerebellum. San Diego: Academic Press, 2000.
19. Forman SD, Cohen JD, Fitzgerald M, Eddy WF, Mintun MA and Noll DC: Improved assessment of significant activation in functional magnetic resonance imaging (fMRI): use of a cluster-size threshold. Magn Reson Med 1995, 33:636-47. | Article | PubMed

20. Owen AM, McMillan KM, Laird AR and Bullmore E: N-back working memory paradigm: a meta-analysis of normative functional neuroimaging studies. Hum Brain Mapp 2005, 25:46-59. | Article | PubMed

21. McAllister TW, Saykin AJ, Flashman LA, Sparling MB, Johnson SC, Guerin SJ, Mamourian AC, Weaver JB and Yanofsky N: Brain activation during working memory 1 month after mild traumatic brain injury: a functional MRI study. Neurology 1999, 53:1300-8. | Article | PubMed

22. Jenkins V, Shilling V, Fallowfield L, Howell A and Hutton S: Does hormone therapy for the treatment of breast cancer have a detrimental effect on memory and cognition? A pilot study. Psychooncology 2004, 13:61-6. | Article | PubMed

23. Bender CM, Sereika SM, Brufsky AM, Ryan CM, Vogel VG, Rastogi P, Cohen SM, Casillo FE and Berga SL: Memory impairments with adjuvant anastrozole versus tamoxifen in women with early-stage breast cancer. Menopause 2007, 14:995-8. | Article | PubMed Abstract I PubMed Full Text

24. Jenkins VA, Ambroisine LM, Atkins L, Cuzick J, Howell A and Fallowfield $\mathrm{L}$ : Effects of anastrozole on cognitive performance in postmenopausal women: a randomised, double-blind chemoprevention trial (IBIS II). Lancet Oncol 2008, 9:953-61. | Article I PubMed

25. Ahles TA, Saykin AJ, McDonald BC, Furstenberg CT, Cole BF, Hanscom BS, Mulrooney TJ, Schwartz GN and Kaufman PA: Cognitive function in breast cancer patients prior to adjuvant treatment. Breast Cancer Res Treat 2008, 110:143-52. | Article | PubMed Abstract | PubMed Full Text

26. Delis D, Kaplan E, Kramer J: Delis-Kaplan Executive Function Scale. San Antonio: The Psychological Corporation. In; 2001.

27. Wechsler D: Wechsler Adult Intelligence Scale (3rd ed. manual). San Antonio: The Psychological Corporation. (Digit Span subtest). In; 1997.

28. Smith A: Symbol Digit Modalities Test. Los Angeles: Western Psychological Services. In; 1982.

29. Wechsler D: Wechsler Abbreviated Scale of Intelligence manual. San Antonio: Harcourt, Brace \& Company. In; 1999.

30. Benton A, Harsher K, Rey G, Sivan A: Multilingual Aphasia Examination (3rd ed.). lowa City, IA: AJA Associates (Controlled Oral Word Association Test, Category Fluency). In; 1994.

31. Wechsler D: Wechsler Memory Scale (3rd ed., abbreviated manual). San Antonio: The Psychological Corporation. In; 1997.

32. Benedict R: Brief Visuospatial Memory Test-Revised (BVMT-R) manual. Lutz, FL: Psychological Assessment Resources, Inc. In; 1997.

33. Rey A: L'examen clinique en psychologie. Paris: Presse Universitaire de France. 1955.

34. Kaplan E, Goodglass H, Weintraub S: The Boston Naming Test (2nd ed.,).Philadelphia: Lea \& Febiger. In; 1983.

35. Jurica P, Leitten C, Mattis S: Dementia Rating Scale-2 (DRS-2) Professional Manual. Odessa, FL: Psychological Assessment Resources. In; 2002.

36. Folstein MF, Folstein SE and McHugh PR: "Mini-mental state". A practical method for grading the cognitive state of patients for the clinician. J Psychiatr Res 1975, 12:189-98. | Article | PubMed

37. Klove H: Clinical Neuropsychology. In: Foster FM, ed. Medical Clinics of North America. New York: Saunders; 1963.

38. Yesavage JA, Brink TL, Rose TL, Lum O, Huang V, Adey M and Leirer VO: Development and validation of a geriatric depression screening scale: a preliminary report. J Psychiatr Res 1982, 17:37-49 | Article | PubMed

39. Grace J, Malloy P: Frontal Systems Behavior Scale (FrSBe): Professional Manual. Lutz, FL: Psychological Assessment Resources. In; 2001.

40. Pezzin LE, O'Niel MB and Nattinger AB: The economic consequences of 
Nattinger et al. Journal of Cancer Therapeutics and Research 2013,

http://www.hoajonline.com/journals/pdf/2049-7962-2-7.pdf

breast cancer adjuvant hormonal treatments. J Gen Intern Med 2009, 24

Suppl 2:S446-50. | Article | PubMed Abstract | PubMed Full Text

41. Yen TW, Czypinski LK, Sparapani RA, Guo C, Laud PW, Pezzin LE and Nattinger AB: Socioeconomic factors associated with adjuvant hormone therapy use in older breast cancer survivors. Cancer 2011, 117:398-405. | Article | PubMed Abstract | PubMed Full Text

\section{Citation:}

Nattinger AB, Pezzin LE, Restrepo JA, Durgerian S, Malkin MG and Rao SM: Cognitive Performance among Breast Cancer Survivors Treated with Aromatase Inhibitors. journal of Cancer Therapeutics and Research 2013, 2:7. http://dx.doi.org/10.7243/2049-7962-2-7 